\title{
Proposal of Improvement for a Textile Finishing Company in the Medellin city Through of Discrete Simulation
}

\author{
Propuesta de Mejoramiento para una Empresa de Acabados Textiles de la Ciudad \\ de Medellín por medio de Simulación Discreta
}

\author{
J.A. Marín- iD ;C.C. Mosquera-Zapata iD ;Y.F. Ceballos iD \\ DOI: https://doi.org/10.22517/23447214.24540 \\ Artículo de investigación científica y tecnológica
}

\begin{abstract}
The textile industry in Colombia is a source of employment for more than $\mathbf{2 0 0 . 0 0 0}$ people and more than $\mathbf{5 0 \%}$ of this production is undertaken in Medellin. Modeling and improving textile processes allow this economic line to be competitive internationally. In this paper, we make a description about the use of discrete event simulation in a textile finishing company through the presentation of the results of four scenarios, which finally shows the potential of discrete simulations in productive environments and its high impact when modelling part of reality without the necessity of experimenting with the real system. The method used in this paper is summarized in three major stages: the first one is the simulation methodology, the second one is the data to support the simulation, and the final stage is an analysis of the results with the comparison of the four scenarios. The simulation was statistically validated and verified with the real behaviors of the company and it is executed by using software tools such as EasyFit ${ }^{\circledR}$, Microsoft Excel ${ }^{\circledR}$ and Simul8 ${ }^{\circledR}$.
\end{abstract}

Index Terms - Discrete event simulation, textile finishes, verification model, validation model.

Resumen - La industria textil en Colombia es fuente de empleo para más de 200000 personas y en la ciudad de Medellín se encuentra más del $50 \%$ de esta producción. La necesidad de modelar y mejorar procesos textiles permite a este renglón de la economía ser competitivo a nivel internacional. En este documento se realiza una descripción acerca del uso de la simulación discreta en una empresa de servicios de acabados textiles, a través de la interpretación de cuatro escenarios; lo que se traduce en demostrar el potencial de la simulación discreta en entornos productivos de servicios y su alto impacto al modelar sin necesidad de experimentar con el sistema real. El método utilizado en el presente escrito se resume en tres etapas, la primera comprende la metodología de simulación, la segunda los datos que soportan la simulación y por último un análisis de resultados con la comparativa de los escenarios. La simulación fue validada

This manuscript was sent on October 21, 2020 and accepted on February 16, 2021.

J.A. Marín is an Industrial Engineer and a student in master's engineering program of Universidad de Antioquia Colombia (e-mail: jalexander.marin@udea.edu.co). estadísticamente y verificada con los comportamientos reales de la empresa y se ejecuta por medio de herramientas de software como EasyFit ${ }^{\circledR}$, Microsoft Excel ${ }^{\circledR}$ y Simul8®.

Palabras claves - Simulación discreta, acabados textiles, verificación y validación.

\section{INTRODUCTION}

$\mathrm{T}$ HE increase of service companies worldwide, and therefore in Colombia, represents for the national industry the key to economic strengthening based on the fact that this sector does not always have dedicated and specialized companies in all clusters and which are neglected by investors; this is how they become a great opportunity for micro and medium-sized enterprises. Large textile companies transfer part of their processes to other small textile companies according to customer demand [1], because if they did not support each other, it would be more costly.

Additionally, textile companies pay high costs for semi-final product waste [2]. The production of small series, mass customization and rapid responses have become increasingly prevalent in the future textile supply chain [3]. Moreover, textile research has been emphasized, for instance, supply chain coordination under energy consumption constraints [4], among other increasingly relevant factors.

In line with the above, the company under study has been providing the textile finishing or manual finishing service, and as its services increase in relation to the cycles of its demands, low and high seasons are generated. Because of the latter, it has become crucial to improve the processes, this behavior requires meeting customers' needs in a timely manner.

This article provides an analysis for different scenarios of the company by using discrete simulation; it considers variations in

C.C. Mosquera is an Electrical Engineer and a student in master's engineering program of Universidad de Antioquia Colombia (e-mail: cristhian.mosquera@udea.edu.co).

Y.F. Ceballos is a Ph.D. in engineering of Universidad Nacional de Colombia and Full-time professor at the industrial department, engineering faculty of Universidad de Antioquia Colombia (e-mail: yony.ceballos@udea.edu.co). 
labor, and the increase of installed capacity or production for new references are contemplated without implying difficulties or productive shutdowns when conducting the experiments; and finally, it is intended to optimize economic resources.

By understanding simulation as a tool of experimentation on a model that imitates reality, and with the aim of gaining an understanding of production systems in the textile finishing company, this article applies the simulation of discrete events, making reference to the modeling of a system as it evolves over time by a representation in which state variables change instantly at separate times [5].

A simulation of the finishing process is introduced for a reference type with Simul8. This tool is implemented with the purpose of determining the maximum level of productivity and the effect that changes can generate, mainly from the perspective of process improvement. Simultaneously, the proposed simulation model will enable to identify possible bottlenecks, or whether there is an over or underutilization of resources. Finally, the improvement proposals are presented, being these consistent and possible as a support for administrative decision making.

\section{THEORETICAL FRAMEWORK}

Textile production requires a systemic analysis where discrete simulation provides two ways for carrying out the study of the system: on the one hand, one can experiment with the system itself, and on the other hand, experiment with a system model. There will be no alteration in the real system since the possibility to test any idea in the model one can arise attractive alternatives that would not have been possible to launch directly in the real system. Consequently, simulation is a technique which involves "the structuring of a model that represents a real situation (system), and then conducting experiments on the model". Hence, it is possible not only to describe how the textile system behaves, but also to analyze what the impact of a decision would be on the system and on each of the actors involved.

The simulated system imitates the operations of the real system over time and thus achieves an appropriate interpretation of the variables which describe the behavior of the problem in reality [5]. Additionally, tracking system state changes as a result of the occurrence of events, or events is another strength to employ such modeling techniques [6].

The current challenge is having the necessary skills to develop such models, which are fundamentally synthesized in the ability to study systems as a whole and in a mind that understands the cause-effect relationships that occur between the different actors that make part of a value network [7].

The qualities of simulation-based verification emerge from the fact that a simulation is like an empirical experiment. In other words, simulation is efficient because the scenarios raised are properly configured, therefore forcing designers to gain more knowledge about the system under study.

The simulation-based verification greatly depends on the proposed scenarios. Similarly, the simulation is performed under a specific set of conditions called the experimental framework [8].
The simulation environment uses a flowchart-based modeling methodology that facilitates the description of discrete event systems. Systems are described using the point of view of the entities that flow through them and the available resources. The models are structured in a hierarchical and modular way. They are defined by a flowchart and static data [9].

In the process of validation and verification $(\mathrm{V} \& \mathrm{~V})$ of the models, it is possible to perform techniques and tests that can be used both objectively or subjectively, making reference in an objective manner to all types of mathematical procedures or statistical tests such as hypothesis tests or confidence intervals [10].

\section{MethodOLOGY}

The methodology implemented to carry out the simulation in the textile finishing company is described below:

Search and selection of the company: It was decided to carry out this work in the textile finishing company because of the arrangement and closeness to provide relevant information that enables modelling the system and presenting alternative solutions.

Model construction: The study of the necessary variables was made to represent the model, relationships, and process flows.

Assumptions of the simulation model: For this model, it is necessary to highlight the following assumptions, since they represent reality in a computerized way and exclude factors that are not controllable within the simulated environment (all of them have been validated with experts in the company):

- The company works 24 hours non-stop.

- A year's work is simulated.

- The machines do not suffer breakdowns during the testing time and are also not enlisted, but their efficiency is $80 \%$ by the loading time.

- $60 \%$ of the garments that arrive in the system must be changed sideways in the process.

- The service time of each workstation is standard and represents the average time observed by the engineering team, plus the supplement.

- Distances are not evaluated so transport times are omitted from the analysis.

- It is assumed that no defective products come out.

- Employees are never absent.

- When a batch arrives at a work center with multiple machines, the one that is empty is occupied.

- $90 \%$ of garments pass the first quality review and the remaining $10 \%$ is returned for crafting.

- $75 \%$ of garments pass the finished product review.

Collection of times, demands: the demands (lot size) and arrival times of the orders were supplied by the company's commercial staff and adjusted to standard probability distributions using EasyFit ${ }^{\circledR}$. As for the times of each process, they are provided by process engineering, specifically for the reference under study.

Simulation of the model in simul8 software: Once the model is defined and the process flow is understood, its respective construction is performed in the Simul8 software. 
TABLE I

GUIDING QUESTIONS FOR SIMULATION VERIFICATION AND VALIDATION

\begin{tabular}{|c|c|c|}
\hline Model type & Verification & Validation \\
\hline \multirow{4}{*}{ Data model } & $\begin{array}{l}\text { Are these discrete or } \\
\text { continuous events? }\end{array}$ & \multirow{2}{*}{$\begin{array}{l}\text { Does the model include } \\
\text { all the elements } \\
\text { considered in the } \\
\text { conceptual model? }\end{array}$} \\
\hline & $\begin{array}{l}\text { Are the statistical measures } \\
\text { formulated correctly? }\end{array}$ & \\
\hline & $\begin{array}{l}\text { Are math and relationship } \\
\text { formulations correct? }\end{array}$ & \multirow{2}{*}{$\begin{array}{l}\text { Does it contain all the } \\
\text { relationships in the } \\
\text { conceptual model? }\end{array}$} \\
\hline & $\begin{array}{l}\text { Are the events formulated } \\
\text { correctly? }\end{array}$ & \\
\hline \multirow{6}{*}{$\begin{array}{l}\text { Conceptual } \\
\text { model }\end{array}$} & $\begin{array}{l}\text { Are the events rendered } \\
\text { correctly? }\end{array}$ & \multirow{3}{*}{$\begin{array}{l}\text { Is the model a valid } \\
\text { representation of the } \\
\text { actual system? }\end{array}$} \\
\hline & $\begin{array}{l}\text { Are the math formulas and } \\
\text { relationships correct? }\end{array}$ & \\
\hline & $\begin{array}{l}\text { Are the statistical measures } \\
\text { formulated correctly? }\end{array}$ & \\
\hline & $\begin{array}{l}\text { Does the code contain all } \\
\text { aspects of the conceptual } \\
\text { model? }\end{array}$ & $\begin{array}{l}\text { Can the model } \\
\text { duplicate the behavior } \\
\text { of the actual system? }\end{array}$ \\
\hline & $\begin{array}{l}\text { Are the statistics and } \\
\text { formulas calculated } \\
\text { correctly? }\end{array}$ & \multirow{2}{*}{$\begin{array}{l}\text { Is the model credible } \\
\text { for system experts? }\end{array}$} \\
\hline & $\begin{array}{l}\text { Does the model contain } \\
\text { coding errors? }\end{array}$ & \\
\hline
\end{tabular}

To do so, it was necessary to adjust the demands and service times to probability distribution standards, and then use them in the model.

Model verification and validation: For the $\mathrm{V} \& \mathrm{~V}$ of the data and the computational models, the guiding questions of Table I [11] are used.

\section{BUILDING THE MODEL}

The field of study of this work was the textile finishing company, a discrete simulation analysis is performed in the most fixed dyeing area.

The analysis of the input data to the simulated model starts with the construction of the flowchart of the process for the reference in study, as shown in Figure 1, which allows the beginning of the flow design of the process in Simul8 as well as letting experts consider if the diagram represents approximately the process. After this representation, service times are associated with each workstation.

Statistical analyzes are carried out for the data of the demand of the reference to determine the probability distributions under which the behaviors of the variables associated with the study case are modeled. Now of carrying out their respective statistical check, they demonstrated an excellent behavior and fit to theoretical distributions. At this point, it is paramount to clarify that the demand data provided is a history of the company's sales in units during a period of one month approximately.

With the aid of Simul8, the data collected from the frequencies and quantities in which batches arrive at the company are captured and modeled by using the function previously defined in the entities to be modeled. In this case, all software tools can be used to validate the data statistically due to a space which is presented with the purpose of validating the model with different seeds, and hence, verifying through confidence intervals whether the input data is viable or not. If any error is detected in the validation of the model, it is recommended to look for the causes of this fact and correct them immediately before continuing its design since there is a possibility that no reliable data could be analyzed.

After taking into consideration the aforementioned conditions and including these data, the locations were entered to the model where work centers will be modeled assigning the operating time, and the route that the material will follow throughout the process will be defined. It means that, for this case, the material flow is established according to the agreed

TABLEII

WORK CENTER DATA

\begin{tabular}{lcccc}
\hline \hline $\begin{array}{c}\text { Work } \\
\text { center }\end{array}$ & $\begin{array}{c}\text { Number of } \\
\text { machines }\end{array}$ & $\begin{array}{c}\text { Number of } \\
\text { operators }\end{array}$ & $\begin{array}{c}\text { Capacity } \\
\text { units }\end{array}$ & $\begin{array}{c}\text { Processing } \\
\text { time per unit } \\
\text { (min) }\end{array}$ \\
\hline Sucker & 3 & 3 & 1 & 0.08 \\
Crafts & 0 & 6 & 1 & 0.7 \\
$\begin{array}{l}\text { Quality } \\
\text { review }\end{array}$ & 0 & 1 & 1 & 0.13 \\
$\begin{array}{l}\text { Centrifuge } \\
\text { Washing }\end{array}$ & 1 & 1 & 50 & 0.19 \\
machines & 5 & 2 & 20 & 0.8 \\
$\begin{array}{l}\text { Dryers } \\
\text { PT quality } \\
\text { review }\end{array}$ & 6 & 2 & 40 & 1.18 \\
\hline \hline
\end{tabular}

restrictions initially, establishing that transport times between locations is zero.

The number of machines, work centers, capacity, operators, and processing time per unit in minutes can be observed in Table II.

Global variables were also defined which were used as accumulators at two specific points of interest, at the beginning and at the end of the process to visualize how many units enter and exit, aiming at having clarity about the performance of the model. This fact complements the verification process since the relation of inputs and outputs of the system should be based on what normally happens for this reference.

The process undertaken on each of the entities is executed using the Simul8 menu properties option, defining at each step the operations and time data presented in the analytical course.

After entering each of the factors that make up the simulation model in Simul8, it proceeds to perform the runs for the stated time, which makes it possible to observe the results. In case of some type of error, it is important to look for the causes of the issue following the instructions generated in the alert messages.

Once it is possible to obtain results, it is validated again to see if they represent reality by means of an analysis of confidence intervals for arrivals and using the expected values of the numbers of arrivals. Furthermore, this fact is determined with the frequencies of occurrence in each event.

In the case of the company, it could be observed that the reality vs the results is approximate, and the arrivals of the model were statistically equal with a significance level of $95 \%$, according to the experts' opinions. In this way, four improvement proposals are introduced, making variations in the 
model, and executing new runs to review and analyze the results, being these the ones of the application of the experimental model. This process is carried out in Excel and will be discussed later.

It is worth clarifying in this section that every day and real models have a high degree of difficulty when modeling them [8]. For this reason, this model presents some assumptions that intend to foresee the aspects in which scope will not be obtained, previously mentioned as assumptions of the simulation model.

\section{A. Model variables \\ 1) Exogenous}

- Process time of each of the locations.

- Daily demand from the entity.

- Time between arrivals in the system.

2) Endogenous

- Process time of each of the locations.

- Daily demand from the entity.

- Time between arrivals in the system.

3) State

- Number of entities in the system at any time.

- Number of inactive locations at any time.

- Number of entities terminated.

- Number of locations in use.

- Number of units in the system.

\section{B. Validation and verification of the model}

In Table III these values are presented, the seeds were chosen randomly, and no verification was used to guarantee their properties.

TABLE III

NUMBER OF ARRIVALS WITH DIFFERENT SEEDS

\begin{tabular}{cccccc}
\hline \hline Test & Seed & Quantity & Test & Seed & Quantity \\
\hline 1 & 9 & 8625 & 16 & 50 & 6263 \\
2 & 11 & 9108 & 17 & 96 & 8694 \\
3 & 62 & 7959 & 18 & 19 & 10642 \\
4 & 52 & 10313 & 19 & 37 & 12379 \\
5 & 35 & 10442 & 20 & 84 & 9891 \\
6 & 99 & 8788 & 21 & 85 & 11984 \\
7 & 86 & 9604 & 22 & 36 & 8942 \\
8 & 80 & 10460 & 23 & 43 & 10677 \\
9 & 31 & 9840 & 24 & 13 & 9359 \\
10 & 14 & 9432 & 25 & 89 & 6348 \\
11 & 16 & 11048 & 26 & 28 & 12530 \\
12 & 51 & 9543 & 27 & 69 & 11558 \\
13 & 38 & 7150 & 28 & 54 & 12313 \\
14 & 46 & 8111 & 29 & 40 & 6301 \\
15 & 6 & 6641 & 30 & 27 & 13751 \\
\hline \hline
\end{tabular}

A test is performed using confidence intervals for the total variable arrivals of the Ref. 1 statistically and with a reliability of $95 \%$ it can be assumed that the expected value is within the limits of the interval, as seen in Table IV .

Table V and VII shows the responses of model validation, which were answered by the company's experts.

The model described below use the ODD + D protocol [16].
TABLE IV

CONFIDENCE INTERVAL TEST RESULTS FOR THE EXPECTED VALUE OF TOTAL ARRIVALS

\begin{tabular}{cccc}
\hline \hline Product & Arrivals & Lower limit & Upper limit. \\
\hline REF 1 & 8.948 & 8.919 & 10.327 \\
\hline
\end{tabular}

TABLE V

VERIFICATION GUIDING QUESTIONS

\begin{tabular}{|c|c|c|}
\hline $\begin{array}{l}\text { Model } \\
\text { type }\end{array}$ & Verification & Response \\
\hline \multirow{5}{*}{$\begin{array}{c}\text { Data } \\
\text { model }\end{array}$} & $\begin{array}{l}\text { Are these discrete or continuous } \\
\text { events? }\end{array}$ & Continuous \\
\hline & $\begin{array}{l}\text { Are the statistical measures } \\
\text { formulated correctly? }\end{array}$ & $\begin{array}{c}\text { He is in search of Engineer } \\
\text { and they accept the } \\
\text { calculations. }\end{array}$ \\
\hline & $\begin{array}{l}\text { Are math and relationship } \\
\text { formulations correct? }\end{array}$ & Yes \\
\hline & $\begin{array}{c}\text { Are the events formulated } \\
\text { correctly? }\end{array}$ & $\begin{array}{c}\text { He is in search of Engineer } \\
\text { and they accept }\end{array}$ \\
\hline & Are the events rendered correctly? & The model fulfilled \\
\hline \multirow{5}{*}{$\begin{array}{l}\text { Conceptual } \\
\text { model }\end{array}$} & $\begin{array}{l}\text { Are the math formulas and } \\
\text { relationships correct? }\end{array}$ & The model fulfilled \\
\hline & $\begin{array}{l}\text { Are the statistical measures } \\
\text { formulated correctly? }\end{array}$ & The model fulfilled \\
\hline & $\begin{array}{l}1 \text { Does the code contain all aspects } \\
\text { of the conceptual model? }\end{array}$ & There is no evidence \\
\hline & $\begin{array}{l}\text { Are the statistics and formulas } \\
\text { calculated correctly? }\end{array}$ & The models fulfilled \\
\hline & $\begin{array}{c}\text { Does the model contain coding } \\
\text { errors? }\end{array}$ & $\begin{array}{c}\text { Errors are presented, which } \\
\text { are corrected }\end{array}$ \\
\hline
\end{tabular}

\begin{tabular}{|c|c|c|}
\hline \multicolumn{3}{|c|}{$\begin{array}{c}\text { TABLE VI } \\
\text { VALIDATION GUIDING QUESTIONS }\end{array}$} \\
\hline Model type & Validation & Response \\
\hline \multirow[b]{2}{*}{ Data model } & $\begin{array}{l}\text { Does the model include all } \\
\text { the elements considered in } \\
\text { the conceptual model? }\end{array}$ & Yes \\
\hline & $\begin{array}{l}\text { Does it contain all the } \\
\text { relationships in the } \\
\text { conceptual model? }\end{array}$ & $\begin{array}{l}\text { Yes, for the model are } \\
\text { included assumptions }\end{array}$ \\
\hline \multirow{3}{*}{$\begin{array}{l}\text { Conceptual } \\
\text { model }\end{array}$} & $\begin{array}{l}\text { Is the model a valid } \\
\text { representation of the actual } \\
\text { system? }\end{array}$ & Yes \\
\hline & $\begin{array}{l}\text { Can the model duplicate the } \\
\text { behavior of the actual } \\
\text { system? }\end{array}$ & If for the study reference \\
\hline & $\begin{array}{l}\text { Is the model credible for } \\
\text { system experts? }\end{array}$ & Yes \\
\hline
\end{tabular}

For research purpose, the potentially recyclable material frames containers and packaging of paper, cardboard, plastic, glass and/or metal that can be recycled, reused, recovered and/or reintegrated into the value chain. The proportion of this material in all waste generated per person in a unit of time is presented as a percentage, and it is assumed that the rest of the waste does not meet those characteristics.

\section{REsults AND ANALYSIS}

The model results were compared in parallel with the four proposals made. Finally, a financial analysis is proposed to 
justify the economic effects that the proposals provide on the value generation for the company.

\section{A. Proposal 1}

Decrease 3 of the washing machines to maximize their use.

\section{B. Proposal 2}

Remove two dryer machines whose upper capacity is subsequent than the point where bottlenecks and washing machines are hypothetically presented.

\section{Proposal 3}

Hire 3 operators for the washing machines since this work center is impacted with downtime in the machine caused by the multiple displacements of the operators. The purpose would be that new people make the trips, and whoever is in the work center dedicates exclusively to loading and commissioning the equipment.

\section{Proposal 4}

Combine the 3 previous proposals to review the sensitivity of the system to parallel modifications when comparing the results with the unmodified model.

The financial result performed is presented below by using the results obtained from the simulation and performing calculations with the variables of the number of units processed that the model throws. The runs for each proposal were carried out on an equal basis of simulation time conditions.

From a financial perspective, the result is not satisfactory for Proposal 1, which is not important in Proposal 2, but very representative in Proposal 3 and Proposal 4, being Proposal 3

TABLE VII

FINANCIAL RESULTS FOR MODELING THE FOUR SCENARIOS IN A MONTH OF TESTING RUN USING THE DUPPON MODEL

\begin{tabular}{ccccc}
\hline \hline Proposal & P 1 & P 2 & P 3 & P 4 \\
\hline $\begin{array}{c}\text { Additional revenue } \\
\text { from higher sales } \\
\text { volume per month }\end{array}$ & $-\$ 720.00$ & $\$ 0$ & $\$ 42.792 .000$ & $\$ 41.784 .000$ \\
\hline \hline
\end{tabular}

the one that generates more profits for the company. This situation is evident in Table VII, the results were tested with the Dupont method ${ }^{1}$

It is important to rescue the value that analysis discrete simulation gives to the company. If there had been any changes in the actual system, there would be no prior certainty of the expected results, decision-making may be wrong or biased for any of the improvements.

\footnotetext{
${ }^{1}$ This model was invented by Donaldson Brown, an American electrical engineer who joined the Treasury department of the dupont chemical company in 1914. Years later, DuPont bought 23\% of General Motors' shares and gave Brown the task of straightening out General Motors' finances. Much of the credit for GM's ascension is from Brown's planning and control systems. The success that came in launched the DuPont model towards its pre-eminence in
}

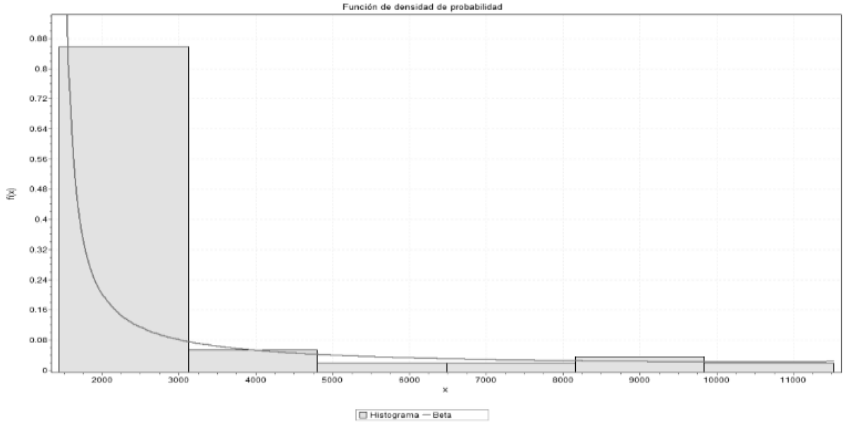

Fig. 1 Density distribution for time adjustment between arrivals

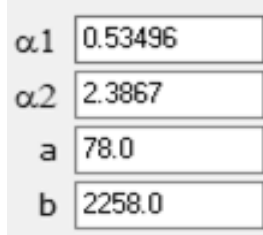

a)

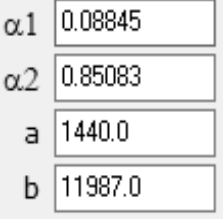

b)
Fig. 2 a) Beta distribution parameters for the number of units per arrival. b) Beta distribution parameters for time between arrivals

Review of the variables of the simulation model and their respective runs

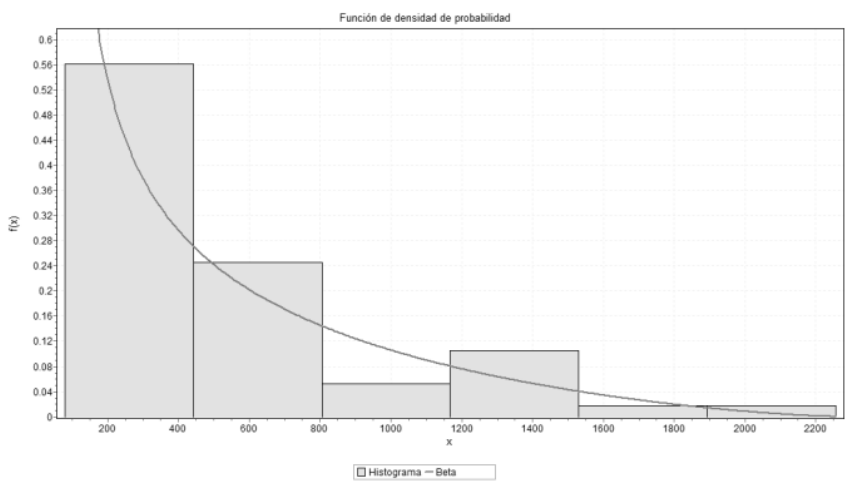

Fig. 3 Density distribution for adjusting number of arrivals per arrival 1) Variable adjustments to theoretical distributions

The time distribution between arrivals conforms to a beta distribution, the parameters and graphs of this setting made in EasyFIT, can be seen in Fig. 1 and Fig. 2a.

For the number of arrivals per arrival the adjustments are made in EasyFit, the data conforms to a Beta distribution, as evidenced in Fig. $2 \mathrm{~b}$ and Fig. 3.

The parameterization of service times is evident in the courses presented above, considering that they are measured in the study model and they are deterministic in nature. Consequently, there was not enough information to give them probabilistic character because it can somehow limit the results. What is significant for the study is being able to make variations to the model and determine the best option based on the fact

all major corporations in the U.S. and remained the dominant form of financial analysis until the 1970s.

In simple terms, what is sought is to express the company's ROE based on three components, namely one. Profit margin or operational efficiency; Two. Asset rotation or efficiency in asset use; And three. The capital multiplier or the degree of financial leverage. 
that, although the results are not exactly real, it Is behavior does reflect the reality.

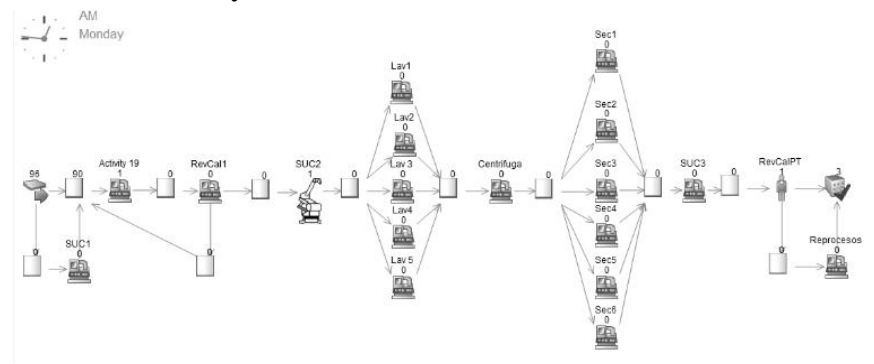

Fig. 4 Graphical representation of the model in Simul8

\section{2) Simul8 Results}

When simulating the model for one month with 7217 units arrive to be processed by the line, this is contrasted with the actual values of the company, according to the expert's criteria.

.If the cost is supposed to be correct, the best proposal would be the 3 one, despite not being the one that maximizes efficiencies, it keeps constant the costs vs units produced and generates the best financial indicators according to the evaluated model. Fig. 4 shows the Simul8 representation of the

TABLE VIII

METRICS OF ENTITIES IN THE SYSTEM

\begin{tabular}{lc}
\hline \hline \multicolumn{1}{c}{ Base Run } & Trial Average \\
\hline End 1. Average Time in System & 152 \\
End 1. Number Completed & 7716 \\
End 1." In System Less Than" time & 10 \\
End 1. \% In System Less Than Time Limit & 4 \\
End 1. St Dev of & 120 \\
End 1. Maximum Time in System & 510 \\
End 1. Minimum Time in System & 3 \\
\hline \hline
\end{tabular}

model

Initially, as observed in the plant, it is assumed that the bottlenecks, and long storage and waiting were generated by the locations of simple capacity. However, it is observed with the simulation that the hypothesis previously raised was wrong and the bottleneck of the process was in the operators of the washing machines. This fact that reaffirms the advantages of simulation as support in decision-making.

In Table VIII it is possible to observe some of the results of the simulation.

\section{Conclusions AND Future RESEARCH}

Concerning the information entered and analyzed in this article for the case of application in the textile finishing company, the simulation of discrete events was used. It allowed in a structured manner to represent the model associated with the process. Some assumptions were taken as 24 hours work without stops and that the machines do not suffer breakdowns in order to decrease the complexity of the system without straying much from reality .It was tested by confidence intervals of the arrivals variable with a reliability of $95 \%$, the results were in the expected ranges. The seeds were also randomly assigned. With the model already proposed, the Simul8 tool was validated and verified, of the four proposals made, we proceed to select number three, therefore it is decided to make changes to optimize the results. Furthermore, it was found that the bottlenecks of the process were in the operators section of the washing machines. The changes would be beneficial to meet the commitments related with customers and report economic gains for the company.

\section{REFERENCES}

[1] P. Hadaya and L. Cassivi, "The role of joint collaboration planning actions in a demand-driven supply chain," Ind. Manag. Data Syst., vol. 107, no. 7, pp. 954-978, 2007, DOI: 10.1108/02635570710816694.

[2] K. Ma, S. Thomassey, and X. Zeng, "Development of a central order processing system for optimizing demand-driven textile supply chains: a real case based simulation study," Ann. Oper. Res., vol. 291, no. 1-2, pp. 627-656, 2020, DOI: 10.1007/s10479-018-30002.

[3] T. M. Choi and S. Guo, "Responsive supply in fashion mass customisation systems with consumer returns," Int. J. Prod. Res., vol. 56, no. $10, \quad$ pp. 3409-3422, 2018, DOI: 10.1080/00207543.2017.1292065.

[4] H. L. Chan, B. Shen, and Y. Cai, "Quick response strategy with cleaner technology in a supply chain: coordination and win-win situation analysis," Int. J. Prod. Res., vol. 56, no. 10, pp. 33973408, 2018, DOI: 10.1080/00207543.2016.1278283.

[5] A. Law and W. D. Kelton, Simulation Modeling and Analysis, Fifth Edit. Tucson: McGraw-Hill, 2013.

[6] J. C. Puche Regaliza and J. Costas Gual, "The Favorable Effect of the Lean Manufacturing Paradigm on Defect Reduction. Discrete Simulation Techniques," An. That's it. Economics and Empres., vol. XXI, pp. 75-103, 2011.

[7] T. L. Bermúdez Correa and D. A. Carreño Dueñas, "Towards the use of simulation as a tool for the analysis of investment projects," Rev. Investig. Development and Innovation, vol.1, no. 2, pp. 40-52, 2011.

[8] A. Yacoub, M. E. A. Hamri, and C. Frydman, "DEv-PROMELA: modeling, verification, and validation of a video game by combining model-checking and simulation," Simul. Trans. Soc. Model. Simul. Int., pp. 1-30, 2020, DOI: 10.1177/0037549720946107.

[9] W. D. Kelton, Simulation With Arena, Sixth Edit. New York: McGraw-Hill Education, 2015.

[10] R. G. Sargent, "Verification and validation of simulation models," J. Simul., vol. 7, no. 1, pp. 12-24, 2013, DOI: 10.1057/jos.2012.20.

[11] E. Acosta, F. Chiodi, M. Fernández, A. Tcach, and J. Francesconi, "Stages of Validation and Verification in the Construction of Models for the Simulation of Industrial Processes," Inst. Ind., vol. 43, no. 29, pp. 1-8, 2016, [Online]. Available: http://www.edutecne.utn.edu.ar/coini_2016/trabajos/F003_COINI2 016.pdf.

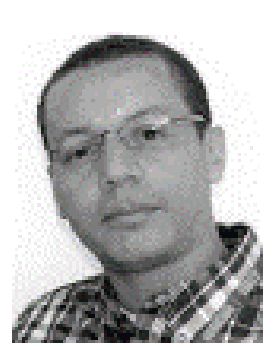

Y.F. Ceballos was born in Guatape, Antioquia, Colombia in 1979. He received the Computer engineering (B.S.), M.S and $\mathrm{Ph} . \mathrm{D}$. degrees in computer science from the Universidad Nacional de Colombia, Medellin, in 2004, 2007 and 2015, respectively.

From 2005 to 2013, he was a professor with the computer science Department. Since 2014, he has been an Assistant Professor with the Industrial Engineering Department at Universidad de Antioquia. He is the author of more than 20 articles in the past years. His research interests include numerical methods, game theory, system simulation, behavioral research, algorithms, and stochastic processes. 
Dr. Ceballos is an actual member of Society for Industrial and Applied Mathematics (SIAM) and the system dynamics society (SDS).

ORCID: https://orcid.org/0000-0001-5787-8832

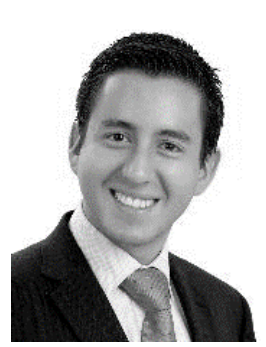

J.A. Marin was born in Sonsón, Antioquia, Colombia in 1982. He received his degree in Industrial Engineering (B.S.), from the Universidad de Antioquia, Medellin, in 2014.

$\mathrm{He}$ is a master's degree student (M.S.) at University of Antioquia, Medellin. His research interests include continuous improvement, discrete-simulation, agentbased modeling (ABM), process indicators, neural network, dynamics system, Kaizen

From 2015, He has worked in different industries in the private sector, including textile, agricultural, and construction companies, and currently performs continuous improvement functions for the financial vice-presidency of a renowned LatinAmerican insurance company.

ORCID: https://orcid.org/0000-0001-6625-1783

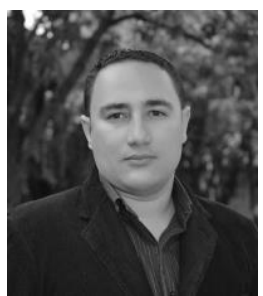

C.C. Mosquera Zapata was born in Cali, Valle del Cauca, Colombia in 1987. He received his degree in Electrical Engineering (B.S.), from the University of Valle, Cali, in 2012. He is a master's degree student (M.S.) at University of Antioquia, Medellin. His research interests include agent-based modeling (ABM), efficient energy use, neural network, electrical machines, electric transportation technology and dynamics system. From 2013, He has worked in different industries in the private and public sector, including educational and construction companies, and currently it is conducting activities independently in the electricity sector.

ORCID: https://orcid.org/0000-0003-3143-7718 